\title{
Feature
}

\section{Approaches to Biology Teaching and Learning}

\section{Putting the Horse Back in Front of the Cart: Using Visions and Decisions about High-Quality Learning Experiences to Drive Course Design}

\author{
Deborah Allen* and Kimberly Tanner ${ }^{+}$
}

*Department of Biological Sciences, University of Delaware, Newark, DE 19716; and 'Department of Biology, San Francisco State University, San Francisco, CA 94132

\section{COMMON STRATEGIES FOR DESIGNING A COURSE}

Envision the following two scenarios about two instructors faced with the task of teaching a course in the life sciences. The first scenario goes something like this:

Chris has been a college professor for 4 years, and for three of them, has taught an 80-student section of a middletier course in cell and molecular biology, a course required of all biology majors. Another section of the course has been taught for the past 12 years by a more senior colleague. When Chris first started teaching, he and his colleague sat down together and decided on a common list of content topics that they would cover and chose the same textbook. They agreed that they would work independently on the teaching strategies they would use for each topic. Chris planned to use some approaches he observed while serving as a teaching assistant at his doctoral institution. Now, 3 years into the course, despite good student ratings of his teaching efforts, Chris is somewhat dissatisfied with what he has accomplished. He thinks his attempts to make the subject matter relevant by bringing "hot topics" from the biomedical research-relevant news into his lectures have been only mildly successful at stimulating student interest. In addition, students seem to do poorly on exam questions in which he asks them to connect these topics from current research findings to the material they read in the textbook and that is covered in lectures. The undergraduate interns working in his research lab seem to be far more engaged in learning about cell biology, and he wonders if there isn't some way to capture this interest for the general population of students in his class. But redesigning the course will be time-consuming and may run into resistance from his senior colleague.

Pat has been teaching for 6 years at a large research university-she was hired to coordinate the introductory

DOI: $10.1187 /$ cbe.07-03-0017

Address correspondence to: Deborah Allen (deallen@udel.edu). biology laboratory experience and to teach one of the largeenrollment sections of this two-semester course. Pat is one of six instructors who teach the multisection course each semester. The instructors meet regularly, and once a year they have a retreat at which they discuss the course; the instructors routinely agree that it is in the best interests of the students for them to use the same textbook in all sections of the course and to cover the same scope of topics in the same sequence. Pat feels that this has led her to compromise on the teaching strategies she would like to use in her section but feels that her role as primary decision-maker for the lab curriculum has helped to allay her concerns. The design of all of the labs includes opportunities for students to depart from "cookbook" approaches-once they have learned a basic procedure and run a prescribed experiment, students spend the rest of the lab period and sometimes the next lab designing and running an experiment to test their "next questions." However, she's begun to hear more and more frequently from the other course instructors that no matter what they seem to do, the students tell them on course evaluations that they don't feel that their learning experiences in the lab connect well, if at all, to those in the lecture. Unfortunately, Pat has to admit that her students have expressed the same concerns.

Each of these scenarios describes a conscientious instructor who is operating in a situational context that drives the most common approach to course design. This most common approach basically entails the creation of a list of topics and then the development of a set of lectures to cover the progression of ideas falling under the scope of those topics. The topics are commonly chosen to reflect the material presented in a textbook, to prepare students for following courses, or to reflect time-honored traditions-or the interests of the instructor-and are limited simply by the number of such topics that will fit in the allotted meeting time for the course. The sequencing of the chosen topics likewise typically mirrors that of the textbook chapters. The goal of having students "understand the material" is the tacit assumption underlying this approach (Fink, 2003). In addition, Pat and Chris appear to have incorporated learning goals 
related to science literacy and critical thinking into their course design decisions for lecture or lab. However, the messages sent to students by the lecture approach about the nature of science and about how people learn science seem to predominate. Students seem to view the class activities chosen to support these more ambitious goals as a disconcerting, disorganized sidetrack from their attempts to really understand the material.

\section{ANOTHER WAY TO DESIGN INSTRUCTION}

Another, more systematic approach to designing significant learning experiences, often referred to as the "backward design process," has been popularized by Wiggins and McTighe (1998) and is included as a central feature of Fink's model for integrated course design (Fink, 2003). The process is referred to as backward because it starts with a vision of the desired results. The design process then works backward to develop the instruction. The design choices that constitute the beginning of the process in the common model of course design (described above in the Chris and Pat scenarios) would be made toward the end of the backward design process and would not drive the curriculum. How you teach might become as important as what you teach.

\section{The Backward Design Model of Wiggins and McTighe}

The Wiggins and McTighe design model, most popular in the $\mathrm{K}-12$ instructional setting, divides the instructional planning sequence into three distinct stages (Wiggins and McTighe, 1998), listed below:

Stage 1: Identify desired results: What is worthy of requiring student understanding?

Stage 2: Determine what constitutes acceptable evidence: What would demonstrate competency or gains in student understanding?

Stage 3: Plan learning experiences and instruction: Which approaches promote understanding, interest, and competency in the subject matter?

We will not elaborate here on Stage 3 of this process other than to point out that the design criteria for this stage, planning the actual classroom experiences, are symbolized by the acronym "WHERE" in the Wiggins and McTighe model. Classroom experiences are effective when they show where the ideas are headed, hook the students, explore the subject and equip the student to explore, incorporate a phase for students to rethink their work and ideas, and include an evaluation of results. These criteria strongly resemble those of the "5 E" inquiry learning cycle (Biological Sciences Curriculum Study, 1993) and are not the most unique feature of the backward design process. Rather, the value of the model lies in the way it systematically begins the process with Stages 1 and 2 before laying out a lesson or unit of instructionessentially placing the "horse" of alignment of outcomes and assessment back in front of the "cart" of instructional design.

Enduring Understandings. In their thorough articulation of the possibilities when it comes to setting goals and objectives for student learning, Wiggins and McTighe (1998) make a clear distinction between material that is simply worth covering and what they refer to as "enduring understandings."
These enduring understandings encompass not only the "big ideas" at the heart of a given discipline but also those ideas that have value beyond the classroom-the knowledge and skills that will inform students' thoughts and actions when they graduate from school. Implicit in this notion of enduring understandings is the suggestion that these are the ideas and processes with a broad intellectual focus and with the most potential for motivating student interest and engagement. Thus, in the Stage 1 process, instructional designers are encouraged to look beyond the immediate, to look ahead to what they want students to have accomplished by the end of the unit of instruction, and at what will remain with them going forward. The process is guided by the designer's continuous consideration and reconsideration of the following driving questions:

- To what extent does the idea, topic, or process being considered as an objective reside at the heart of the discipline?

- To what extent will the idea or process have enduring value beyond the classroom?

- To what extent does the idea, topic, or process offer potential for engaging students?

It is this emphasis on consideration of enduring understandings that can distinguish this stage of the design process from a simple listing of objectives for content understanding. Where articulation with following courses is essential (i.e., where the course being designed serves as a prerequisite for following courses), it may be necessary to apply the same analysis to the upper-level course to be served. However, this type of consideration of the articulation of content throughout a curriculum is not explicitly addressed in the Wiggins and McTighe model.

One additional point warrants discussion. Wiggins and McTighe (1998) do not oversimplify what it means to have a mature and enduring understanding. Their analytical framework for mature understanding parses understanding into six facets. These facets are considered to be overlapping and are designed to connect in a practical and immediate way with teaching and assessment practices. Table 1 gives a brief description of the six facets and contrasts them with the degrees of understanding characterized by Benjamin Bloom and colleagues (Bloom, 1956), the subject of a previous Approaches to Teaching and Learning Feature (Allen and Tanner, 2002), and with Fink's taxonomy of significant learning.

What Evidence Is Acceptable? As mentioned previously, a powerful aspect of the backward design process is its insistence that instructional designers determine what constitutes evidence of competency for each of the outcomes envisioned for students in Stage 1. Such evidence comes not only from formal educational research findings but also from the more accessible routes of observation of students and assessment of their work in the course of instruction. However, Wiggins and McTighe do not exempt this classroom research from passing through such filters as validity, reliability, feasibility, and authenticity. They distinguish three types of assessment that have the potential to pass through these filters to provide acceptable evidence of competency in their six facets of mature understanding. Assess- 
ing a given desired outcome may require use of more than one of these types:

- Criterion-referenced assessments: the familiar exams, quizzes, writing, etc., but administered on a reiterative basis so that progress toward development of understandings can be monitored.

- Unprompted assessment and self-assessment: observations of students working together, journals, portfolios, dialogues, class discussions, etc.

- Performance tasks: concrete demonstrations of ability to perform a procedure, design and implement projects and experiments, etc.

These first two design stages can readily induce a powerful transformation in educators who use backward design principles. Faculty are confronted with and forced to examine their values and practices and in doing so often come to two important realizations: 1) their teaching repertoire must be expanded beyond lecturing on a sequence of topics if promoting enduring understandings of the type described above is the desired outcome; and 2) overreliance on textbooks to guide instructional choices has inadvertently led to padding of the curriculum with far more topics, subtopics, and vocabulary than the typical person can reasonably hope to grasp within the context of an ongoing learning experience (American Association for the Advancement of Science [AAAS], 2001). Much of the material of their time-honored curriculum must thus be jettisoned before moving to Stage 3 - the creation of significant learning experiences.

\section{TOWARD A LEANER CURRICULUM}

The AAAS Project 2061 (AAAS, 2001) makes a cogent case for the need to prune the typical science curriculum. For various science, technology, and math disciplines, scientists and educators working under the auspices of this organization conducted an analysis that compared typical textbook coverage of various topics with the learning goals iterated in the Benchmarks for Science Literacy (AAAS, 1993) and the National Science Education Standards (National Research Council, 1996). In determining whether a subtopic qualified for the "candidates for culling list," the participants essentially conducted a cost-benefit analysis-whether the topic's importance to science literacy was in proportion to the amount of time students would need to spend learning the key ideas associated with it. Not surprisingly, many apt candidates for pruning were identified. If the "tyranny of the textbook" can be addressed in this way, there in theory will be more time left for high-priority learning goals.

While to the authors' knowledge such a thorough analysis has not been conducted in the same way for college-level textbooks (perhaps because of the absence of the driving force of a uniform set of standards analogous to the National Science Education Standards), any educator who has taught introductory and middle-tier courses by necessity conducts

Table 1. Side-by-side comparison of three analytical frameworks for elaborating facets or levels of understanding: Bloom's taxonomy of educational objectives (Bloom, 1956), Wiggins and McTighe's facets of understanding (Wiggins and McTighe, 1998), and Fink's taxonomy of significant learning (Fink, 2003)

Bloom's taxonomy of educational objectives ${ }^{\mathrm{a}} \quad$ Facets of understanding ${ }^{\mathrm{b}} \quad$ Taxonomy of significant learning ${ }^{\mathrm{c}}$

Knowledge—recalling learned information Explain—provide sophisticated and apt

Comprehension-explaining the meaning of information

Application-applying what one knows to novel, concrete situations

Analysis-breaking down a whole into its component parts and explaining how each part contributes to the whole

Synthesis-assembling components to form a new and integrated whole

Evaluation-using evidence to make judgments about the relative merits of ideas and materials explanations and theories that provide knowledgeable and justified accounts of phenomena, facts, and data

Interpret-interpretations, narratives, and translations that provide meaning; make subjects personal or accessible through images, anecdotes, analogies, and models

Foundational knowledge - the facts, terms, formulas, concepts, principles, etc. that one understands and remembers

Application-using critical, creative, and practical (decision-making, problem-solving) skills

Apply — ability to use and adapt what one knows to new situations and in various contexts

Have perspective-critical and insightful points of view; see the big picture

Empathize-ability to get inside another's feelings and perspectives; use prior indirect experience to perceive sensitively

Have self-knowledge-perceive how one's patterns or thought and action shape and impede one's own understanding
Integration-making connections among ideas, subjects, and people

Human dimensions-learning about and changing one's self; interacting with others

Caring-identifying and changing one's feelings, values, and interests

Learning how to learn-becoming a better, self-directed learner; learning to ask and answer questions

a The cognitive levels in Bloom's taxonomy are listed in ascending order (from top to bottom) of cognitive difficulty.

${ }^{\mathrm{b}}$ Descriptors reproduced and/or paraphrased from Wiggins and McTighe (1998).

${ }^{\mathrm{c}}$ Descriptors reproduced and/or paraphrased from Fink (2003). 
at least an informal trimming process when teaching the course. Who can fail to be aware that the typical life sciences textbook contains too much material for the typical one- or even two-semester course? The backward design process in essence calls for a more intense and purposeful reflection on why we teach what we do-what is really worthy of requiring student understanding?

\section{INTEGRATED COURSE DESIGN: ANOTHER MODEL FOR THE COLLEGE EXPERIENCE}

Although awareness of and use of the Wiggins and McTighe backward design model is finding its way into the college environment (Miskowski et al., 2007), many educators in this setting prefer a new design model developed by L. Dee Fink: integrated course design (Fink, 2003). The integrated model expands the course instructional design process by first considering the multifaceted realities of the designer's situational context. It then goes on to integrate specific learning experiences into an entire course and concludes by addressing such pragmatic matters as the messages conveyed in the course syllabus. However, this model still maintains the powerful backward design process as its core. The Wiggins and McTighe backward design process focuses more on particular lessons and units of instruction, while acknowledging the influence of national and local science education standards on decisions that are made about desired outcomes.

The integrated course design process of Fink incorporates three distinct phases, each of which in turn includes at least several discrete, sequentially building steps in the design or redesign of a course. These phases are briefly described below.

\section{Beginning Phase: Building Strong Primary Components}

This phase begins with a gathering of information about the situational factors that surround and are likely to influence the course design and implementation-factors such as student, department, institutional, professional society, and community expectations for the course, the nature of the subject, special challenges, the characteristics and values of the teacher, and how the course may or may not integrate into a larger curricular context. Review and reflection on the possible influence of these factors is considered an important first step to making decisions about how students will be expected to benefit from the course. Steps two through four of this beginning phase are an adaptation of the Wiggins and McTighe (1998) backward design model, as previously described. However, the integrated course design model carries its own version of facets of understanding, Fink's taxonomy of significant learning (Fink, 2003; see Table 1). As is the case for the six facets of understanding of Wiggins and McTighe (1998), and in contrast with Bloom's taxonomy (Bloom, 1956), the objectives distinguished within the taxonomy are not ordered within a hierarchical framework. Fink instead intends them to be viewed as overlapping, and in fact interactive and potentially cogenerative in the sense of stimulating one another. The concept of enduring understandings is embedded and pervasive. The model in addition emphasizes what Fink refers to as "forward-looking" assessment-the types of evidence-gathering strategies that incorporate knowledge and skills that people use outside of school. The fifth and final step of this beginning phase is the first step in integration: an initial check of whether the primary components, the learning goals and assessment, are truly in alignment and mutually supportive.

\section{Intermediate Phase: Assembling the Components into a Coherent Whole}

Here the explicit goals of integrated design begin to depart from the original backward design model. The three steps of this process entail the creation of the structure for a course, the selection of instructional strategies, and then the laying out of a careful plan for how each learning activity will unfold (class by class). As is the case for the Wiggins and McTighe model (Wiggins and McTighe, 1998), the careful insistence on consideration of a broad taxonomy of educational objectives (enduring understandings) seldom leads to a choice of lecturing or other forms of direct explanation as the sole or even central instructional activity. For example, if students are expected to become able to make connections among ideas, they will need opportunities to practice and develop that skill within the context of course activities.

\section{Final Phase: Completing the Important Remaining Tasks}

This model does not neglect the nitty-gritty tasks that are part of the college-level educational dynamic. This final phase incorporates four additional steps: 1) determining a grading strategy that reflects the entire scope of the learning goals and activities, 2) anticipating possible problematic issues and fine-tuning the design appropriately, 3) writing a syllabus that conveys the appropriate information about the design to students, and 4) determining what feedback questions and evidence will provide effective information about how the course is going and how it went.

How might the backward design or integrated course design process help Chris and Pat, the two educators whose teaching experiences are captured in the vignettes that open this teaching and learning feature? As part of the process, Chris might realize that his goals for the course had been only vaguely shaped in his mind (and even more vaguely conceived by the students), driven more by the textbook and by his colleague than by his own vision of what is important for his students to understand. He would rethink the ways in which each element of his course conveyed the purpose of the course to his students. By the end of the process, he might be pleasantly surprised to find that his instincts in incorporating the science in the news activity were sound, and that the activity could support and advance his learning goals. He might realize that if he drew students into the activity by giving them a more active role (for example, by investigating the new and important research findings themselves and presenting their findings to their classmates), he could stimulate at least some of the enthusiasm he witnessed in the undergraduates working in his laboratory. Because he would now think of his exam questions 
as evidence that students had in fact met the learning goals, he would craft them in a different, more purposeful way, so that they could be used to monitor students' increasingly more mature and sophisticated understandings of the nature of science in addition to their understandings of cell biology concepts. Pat might re-explore in more specific and in-depth ways what her goals were in incorporating inquiry-based approaches into the laboratory course. With these goals in mind, she could go on to develop activities aligned with these same goals that were suitable for adoption into her lecture class-lecture and lab goals could then be mutually supportive. Both Pat and Chris would be well-served to draw their colleagues into the process-to rethink use of textbooks and to winnow out the "subtopics" that detract from their ability to focus on ways to promote deeper understanding of key ideas. In Pat's case, she might find that her colleagues would be highly receptive to integration of simple inquiry-based activities into their lecture sections as well and that the task of developing and implementing them effectively would be made that much easier with the contribution of their collective talents.

Undertaking in-depth course review and design using these models is not an experience for the faint-hearted or mildly interested educator but can be very rewarding. Support can come from discussion and planning with likeminded colleagues or from attendance at a variety of workshops, some suitable for individuals and some designed for campus teams. Interested faculty can find the assistance that fits their needs by checking the websites of the authors cited, of others engaged in similar activities (e.g., Smith, undated), of the National Academy of Sciences summer workshops, and of others concerned with science education.

\section{REFERENCES}

American Association for the Advancement of Science (AAAS), Project 2061 (1993). Benchmarks for Science Literacy, New York: Oxford University Press. http://www.project2061.org/publications/bsl/online/bolintro.htm (accessed 12 March 2007).

AAAS, Project 2061 (2001). Unburdening the curriculum. In: Designs for Science Literacy, New York: Oxford University Press. http://www.project2061.org/publications/designs/ch7intro.htm (accessed 12 March 2007).

Allen, D., and Tanner, K. (2002). Questions about questions. Cell Biol. Educ. 1, 63-67.

Biological Sciences Curriculum Study (1993). Developing Biological Literacy. Colorado Springs, CO: Biological Sciences Curriculum Study.

Bloom, B. S. (ed.) (1956). Taxonomy of Educational Objectives: Classification of Educational Goals, Handbook I: Cognitive Domain, New York: Longman.

Fink, L. D. (2003). Creating Significant Learning Experiences: An Integrated Approach to Designing College Courses, San Francisco, CA: Jossey-Bass.

Miskowski, J. A., Howard, D. R., Abler, M. L., and Grunwald, S. K. (2007). Design and implementation of an interdepartmental bioinformatics program across life sciences curricula. Biochem. Mol. Biol. Educ. 35, 9-15.

National Research Council (1996). National Science Education Standards, Washington, DC: National Academy Press.

Smith, K. (undated). Morse-Alumni Distinguished Teaching Professor and Professor of Civil Engineering, University of Minnesota. http://www.ce.umn.edu/ smith/ (accessed 12 March 2007).

Wiggins, G., and McTighe, J. (1998). Understanding by Design, Alexandria, VA: Association for Supervision and Curriculum Development. 